\title{
Design and analysis of linear switched reluctance motor
}

\author{
M. Asyraff Md. Aris' 1 , R. N. Firdaus ${ }^{2}$, F. Azhar ${ }^{3}$, N. A. Mohd Nasir ${ }^{4}$, M. Z. Aishah ${ }^{5}$ \\ 1,2,3,4,5 Faculty of Electrical Engineering, Universiti Teknikal Malaysia Melaka (UTeM), Melaka, Malaysia \\ 1,2,3,4,5Electrical Machine Design Research Laboratory, Centre of Robotics and Automation (CeRIA), UTeM, Melaka, \\ Malaysia
}

\begin{tabular}{l} 
Article Info \\
\hline Article history: \\
Received Oct 30, 2020 \\
Revised Aug 30, 2021 \\
Accepted Sep 14, 2021 \\
\hline Keywords: \\
Average force \\
F\&B application \\
Finite element method \\
LSRM \\
Magnetic flux density
\end{tabular}

\begin{abstract}
This paper proposes a linear switched reluctance motor (LSRM) to replace the conventional serving that is used in food and beverage (F\&B) applications such as a pack of sushi and carbonated drinks. This conventional method is no longer practical as it requires a lot of space which will affect costing and productivity. It's also has another disadvantage, in which it needs frequent maintenance of the rotational motor, gear, and limit switches. Therefore, this research is about the design and analysis of linear switched reluctance motor (LSRM) for F\&B applications. The main objective is to design a LSRM and the finite element method (FEM) is used to simulate the result. The result showed that the $24 \mathrm{~s} / 16 \mathrm{p}$ was the best model for linear switched reluctance motor (LSRM) design. The model had average force (F_avg) of $28.36 \mathrm{~N}$ for input current (I) of $1 \mathrm{~A}$. To conclude, this paper provides a guideline in designing the LSRM for F\&B application.
\end{abstract}

This is an open access article under the $\underline{C C B Y-S A}$ license.

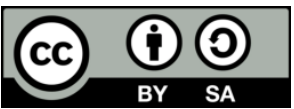

Corresponding Author:

R. N. Firdaus

Fakulti Kejuruteraan Elektrik

Universiti Teknikal Malaysia Melaka (UTeM)

Durian Tunggal, Melaka, Malaysia

Email: norfirdaus@utem.edu.my

\section{INTRODUCTION}

Linear switched reluctance motor (LSRM) is an electromechanical device that develops motion in a single axis without using a mechanism to convert a rotating motion into linear motion. Usually, LSRM is widely used in horizontal applications, such as picking, placement, printing, door elevator, developing actuators and scanning equipment [1]-[5]. Recently, industry and restaurant requirements recommended that more LSRM are to be used for such applications [6]-[8]. The conventional food and beverage application is divided into several main parts, such as sushi conveyer belt, chain, and motor. When food or beverage is placed on a sushi conveyer belt, the chain that is attached to the motor moves the sushi conveyer belt continuously from Point A to Point B [8]-[10]. The conventional F\&B needs an additional space to locate the motor and control panel. Therefore, linear motor (LM) is used to minimise the space used and maintenance of conventional F\&B application. There are several types of LM, such as linear induction motor (LIM), permanent magnet linear synchronous motor (PMLSM) and linear switched reluctance motor (LSRM) [11]-[17].

In recent years, LSRM had increasingly supported as an alternative to other linear motors, such as LIM and PMLSM. This was due to its simple and robust construction with only one-sided concentric windings, which is the stator or translator. Another LSRM advantage is its fault tolerance due to absence of mutual coupling between windings, ease of maintenance and less thermal problems. Other LSRM benefits are in its cooling arrangement and low-cost [18]-[25]. With these advantages, the LSRMs were studied for their suitability in some linear applications, such as in the horizontal linear transportation system. The studies also included high-precision position application in manufacturing automation and cylindrical type linear 
actuator by using an LSRM for applications. However, all these applications require a controlled low-speed linear motion [26].

Therefore, a new LSRM is proposed to replace the conventional F\&B application which allows food and beverage to travel from Point A to Point B without using additional spaces and reduces maintenance, as shown in Figure 1(a). The translator and coil casings are made of aluminium and plastic, respectively. Basically, structure of the proposed LSRM in Figure 1(a) is based on the conventional F\&B application as shown in Figure 1(b).

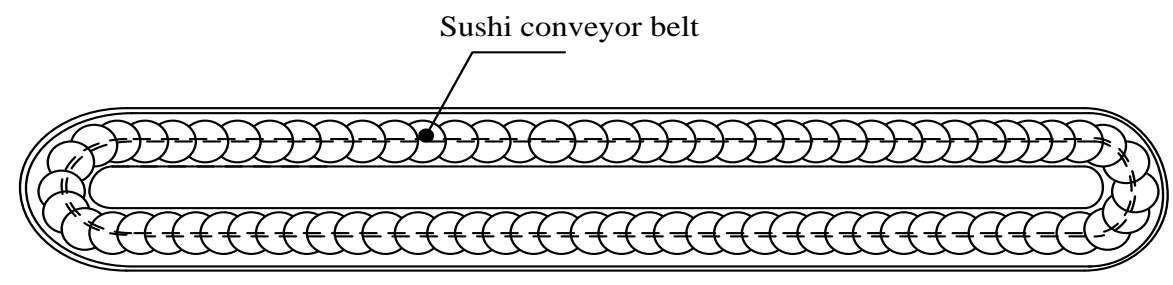

A

B

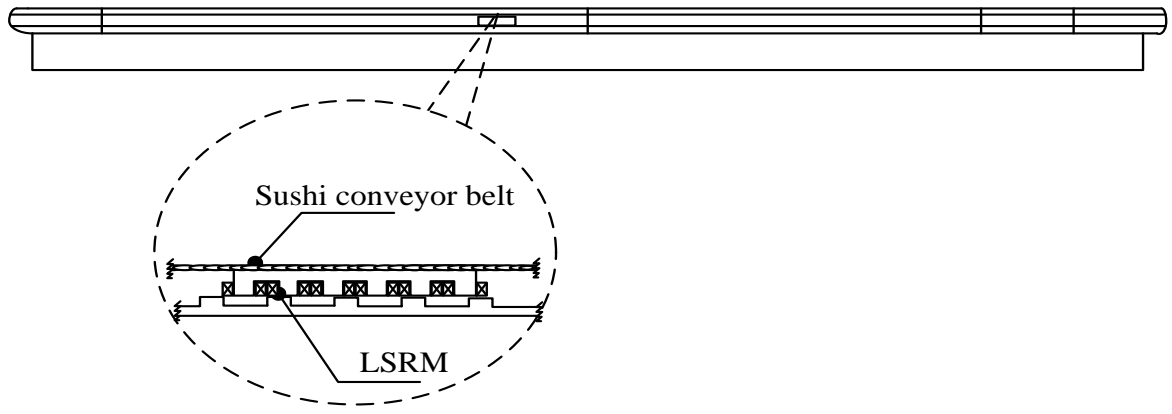

(a)

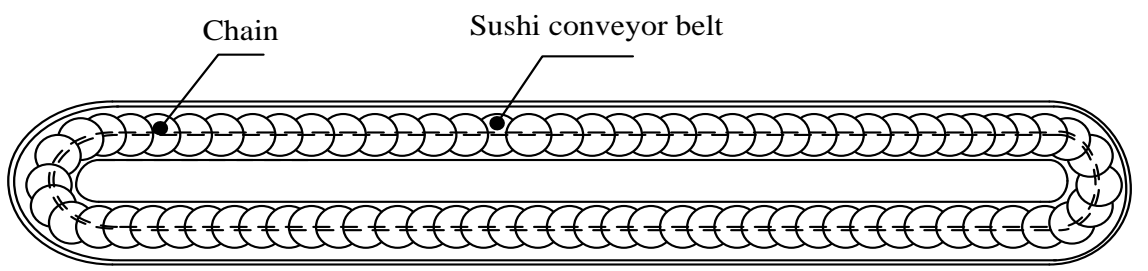

A B

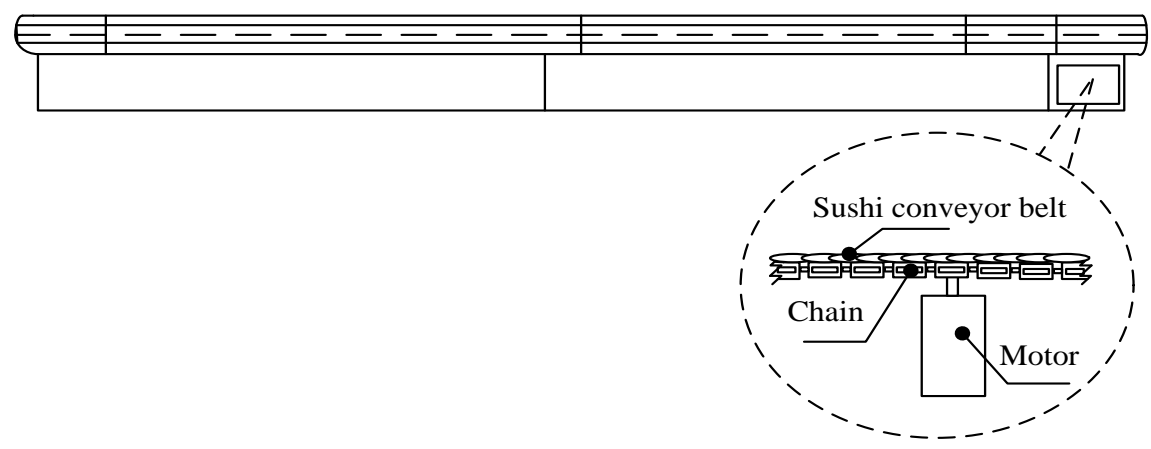

(b)

Figure 1. Innovation of food and beverage application; (a) proposed LSRM and (b) conventional F\&B application [8]

Many studies have extended the research for force/thrust characteristics of LSRM. For instance, Zhao et al. proposed a LSRM analysis and design with force improvement [27]. The aim was to improve the force by using different LSRM pole-arc movers and stators. Furthermore, Amoros et al. studied the LSRM design and performance. The research was to present a design procedure, as well as an experimental and analytical investigation into LSRM [28]. Next, Zaafrane et al. published a paper on design and analysis of a 
double-sided LSRM drive. The research was to present an electromagnetic design of a double-sided LSRM [29]. However, most of the studies focused on LSRM development for transportation application and high performance by using a single or more input current phases for a longer time. None of them focused on designing different number of LSRM turns with specific performance target and simulate the performance by using FEM software.

Therefore, the main objective of this research is to design a LSRM for F\&B application, whereby the LSRM is modelled according to a targeted specification. Therefore, this proposed paper is focused on different number of turns with analysis on average force and magnetic flux density. Finite element method (FEM) by using Ansys Maxwell software is used to compute the average force $\left(F_{\text {avg }}\right)$ and magnetic flux density $(B)$ of LSRM simulation.

\section{DESIGNING OF LSRM.}

In this section, the LSRM was designed at maximum linear velocity of $0.8 \mathrm{~m} / \mathrm{s}$ with acceleration time of $10 \mathrm{~mm}$. The vehicle payload was set at $0.5 \mathrm{~kg}$ to fulfil the requirement performance of average force. All modelling total length of translator $\left(L_{t r}\right)$ was fixed with similar translator and stator height but different slot-pole numbers. The analysis will focus on three model configurations with different number of slots and poles, for example, 6 slots 4 poles, 18 slots 12 poles and 24 slots and 16 poles. The overall LSRM flowchart shows in Figure 2 and Figure 3 shows the basic LSRM structure.

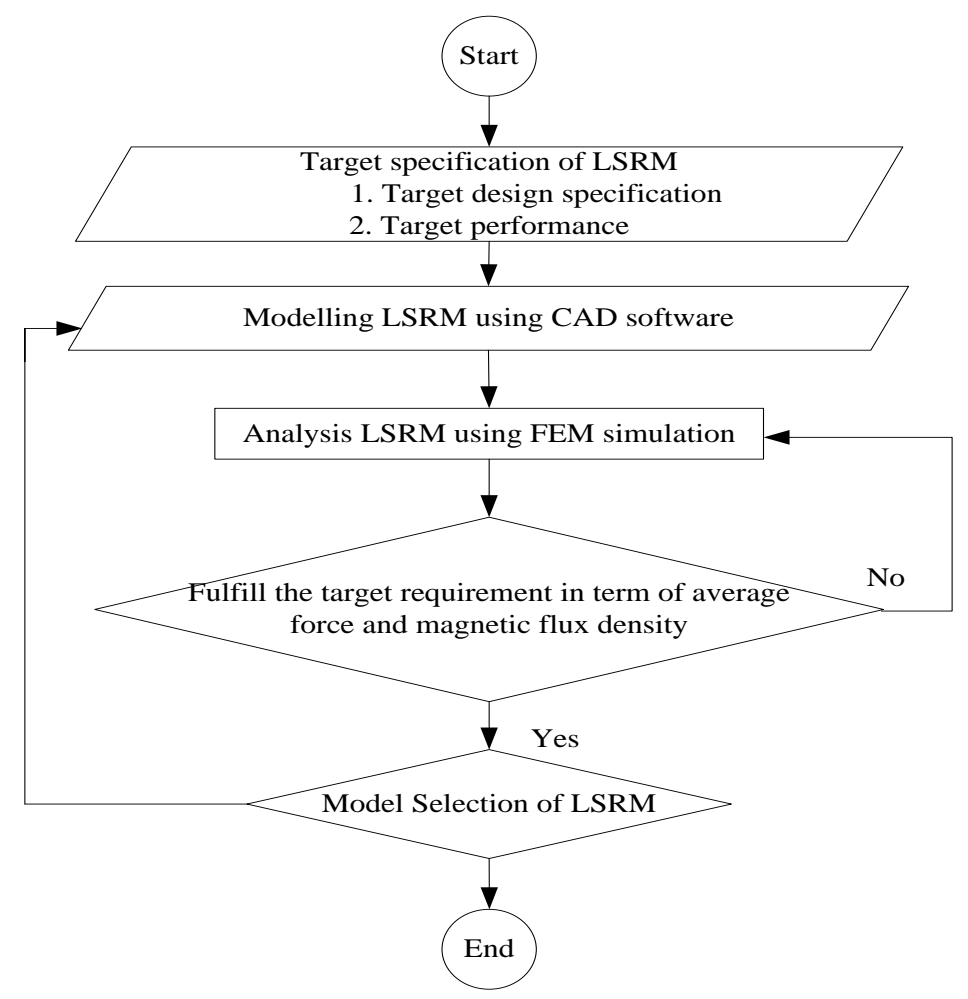

Figure 2. Overall LSRM flowchart

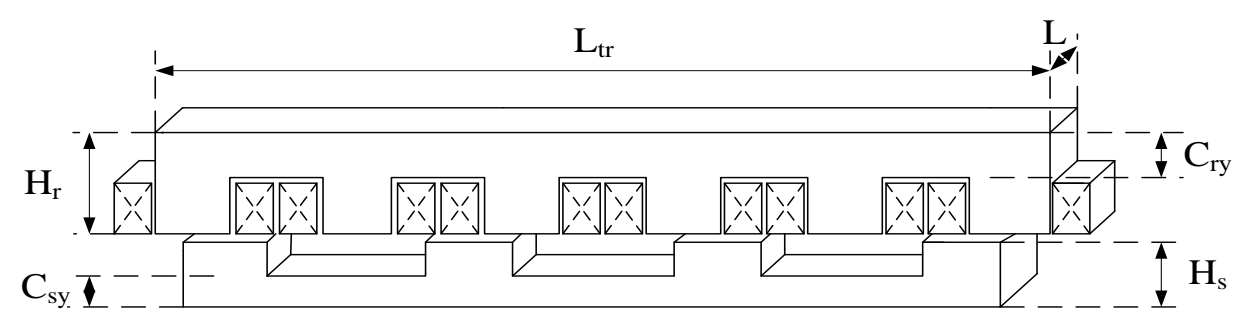

Figure 3. Cross-section view of LSRM in this research 
This section focuses on the overall flowchart of LSRM structure which is design and analysis. The LSRM is designed for three phases. Therefore, the stator slot (s) and pole (p) are set to $6 s / 4 p, 18 s / 12 p$ and $24 \mathrm{~s} / 16 \mathrm{p}$. The stator and translator are designed for the square type. Initially, the design was set to translator length of $165 \mathrm{~mm}$ by considering the force and magnetic flux density that was produced by the LSRM. The thickness of stator yoke is set to be sufficient to limit the flux density, which was below the knee point of B$\mathrm{H}$ curve material, which lest than 1.8T. Identification of the model sizing parameters was referred to the basic specification. Two methods were used to develop the models, which were by calculation and specification after CAD modelling. For direct specification, the given vehicle payload was $500 \mathrm{~g}$, acceleration time $\left(t_{a}\right)$ was $10 \mathrm{~s}$, maximum linear velocity $\left(V_{\max }\right)$ was set as $0.07 \mathrm{~m} / \mathrm{s}$, the bore diameter (D) was $17.2 \mathrm{~mm}$, stator pole angle, $\beta_{s}=0.58$ and $\mathrm{k}$ was set as 2.3. By calculating, the model parameters for LSRM could be determined from the acceleration of the F\&B application found by (1) and the pull force to accelerate the F\&B application was found by (2), respectively [19].

$$
\begin{array}{lrl}
a_{a}=\frac{V_{\max }}{t_{a}} & {\left[\mathrm{~m} / \mathrm{s}^{2}\right]} \\
F_{a}=m a & {[\mathrm{~N}]}
\end{array}
$$

Accordingly, the LSRM's power (P) is calculated by (3) as [19]:

$$
P=F_{a} V_{\max }
$$

The core stack length is written as [20],

$$
L=k D \quad[\mathrm{~mm}]
$$

The stator yoke thickness Csy is given by [20]:

$$
C_{s y}=\frac{D \beta_{s}}{2} \quad[\mathrm{~mm}]
$$

LSRM has salient poles stator and translator in simple structure. The LSRM stator and translator is made of steel (SS400). Meanwhile, the translator has phase windings. However, the stator has no windings or magnet. Table 1 shows the specification after calculation. The process was continued with the determination of the other parameters after the computer-aided design (CAD) software. Therefore, each model will be designed by using the CAD modelling. After designing, all models were exported to FEM for simulation. The analysis consisted of average force and magnetic flux density for different LSRM models. The analysis result of each model was evaluated based on the targeted specification. Then, the best model was selected.

The model was designed with fixed parameters, such as air gap, stack length, thickness, height of translator and stator. The number of coil turns was determined based on the area of coil and fill factor that correspond to coil size. Factor that affected the number of turns was the size of copper wire. Finally, the complete design structure is tabulated in Table 2. Figure 4(a)-(c) shows the three different types of LSRM. The type has been selected which is $6 s 4 p, 18 s / 12 p$ and $24 s / 16 p$. The input current for each model as set from $1 \mathrm{~A}$ to $5 \mathrm{~A}$.

Table 1. Basic specification after calculation

\begin{tabular}{lcc}
\hline \multicolumn{1}{c}{ Specification } & Value \\
\hline Direct & {$[\mathrm{m} / \mathrm{s}]$} & 0.07 \\
Maximum linear velocity, $V_{\max }$ & {$[\mathrm{s}]$} & 10 \\
Acceleration time, $t_{a}$ & {$[\mathrm{Kg}]$} & 0.5 \\
Payload of the vehicle & {$[\mathrm{g}]$} & 1 \\
Air gap length, & {$[\mathrm{mm}]$} & 165.5 \\
Total length of translator, $L_{t r}$ & & \\
Calculation & {$[\mathrm{mm}]$} & 40 \\
Stack length, $\mathrm{L}$ & {$[\mathrm{mm}]$} & 5 \\
Stator yoke thickness, $C_{s y}$ & {$[\mathrm{~mm}]$} & 10 \\
Height of stator pole, $H_{s}$ & {$[\mathrm{~mm}]$} & 12 \\
Height of translator, $H_{r}$ & {$[\mathrm{~mm}]$} & 5 \\
Translator yoke thickness, $C_{r y}$ &
\end{tabular}




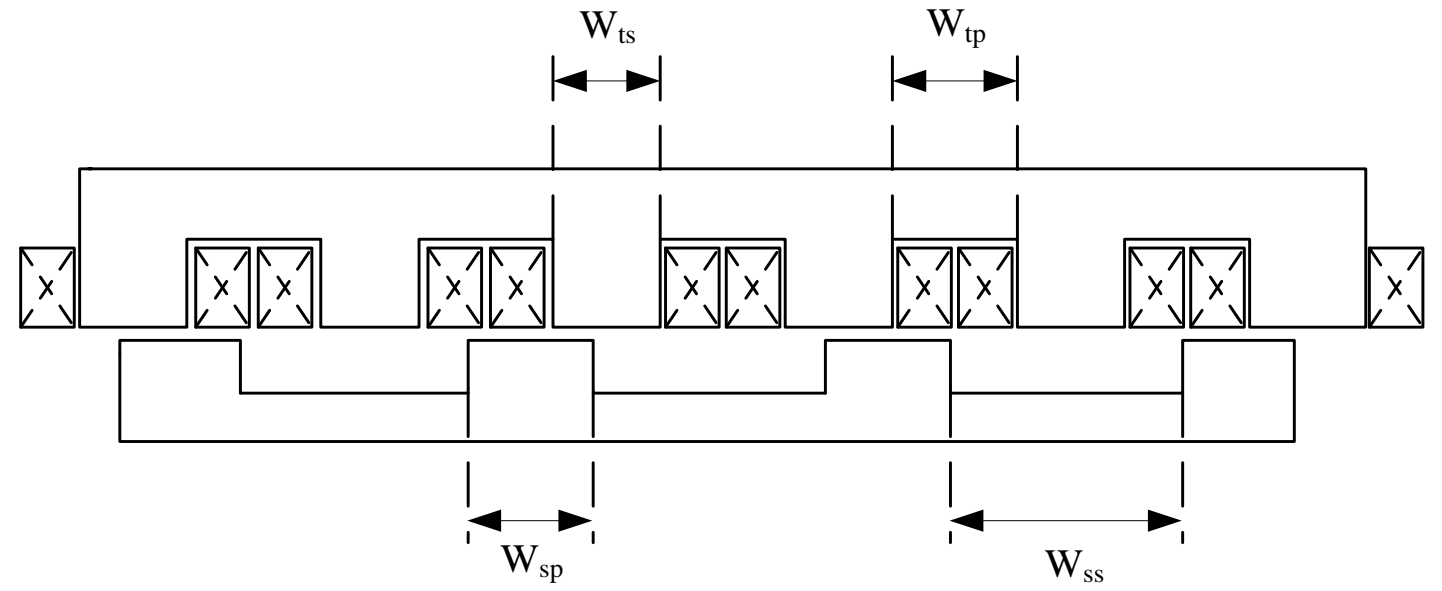

(a)

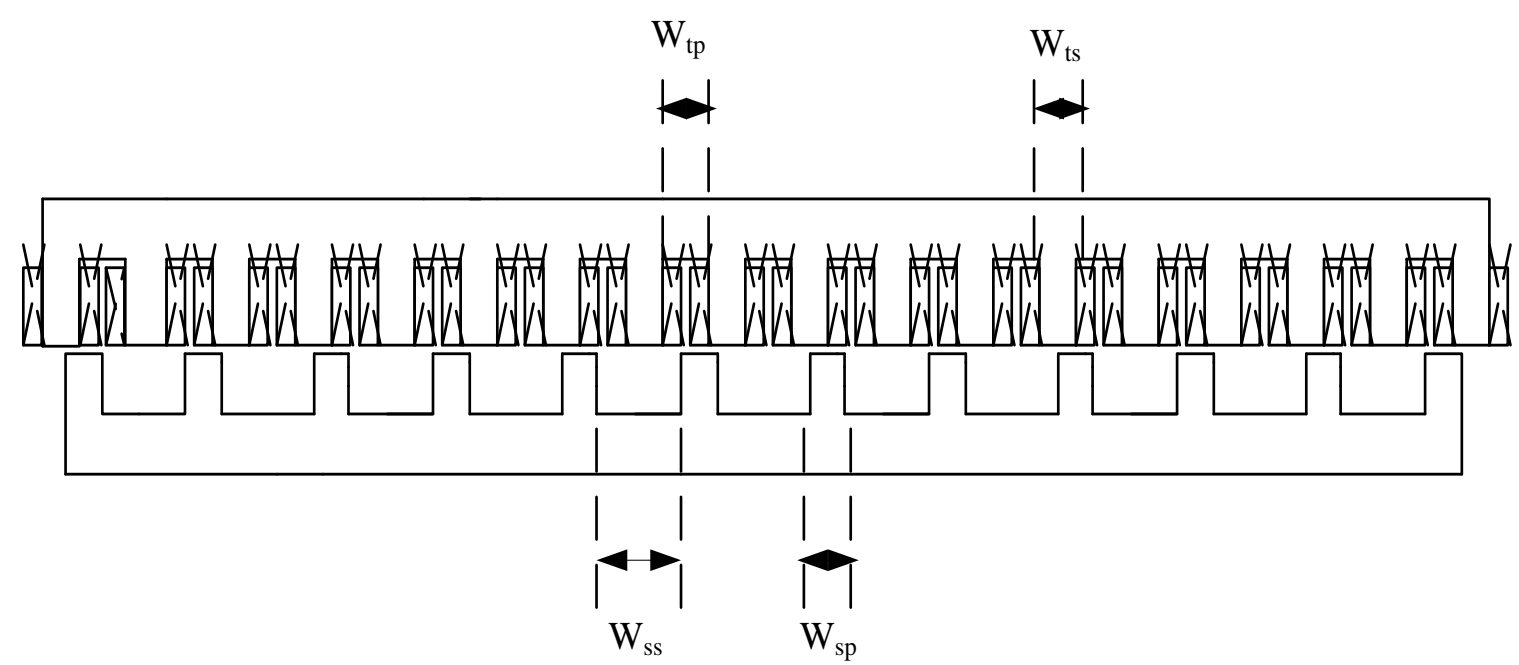

(b)

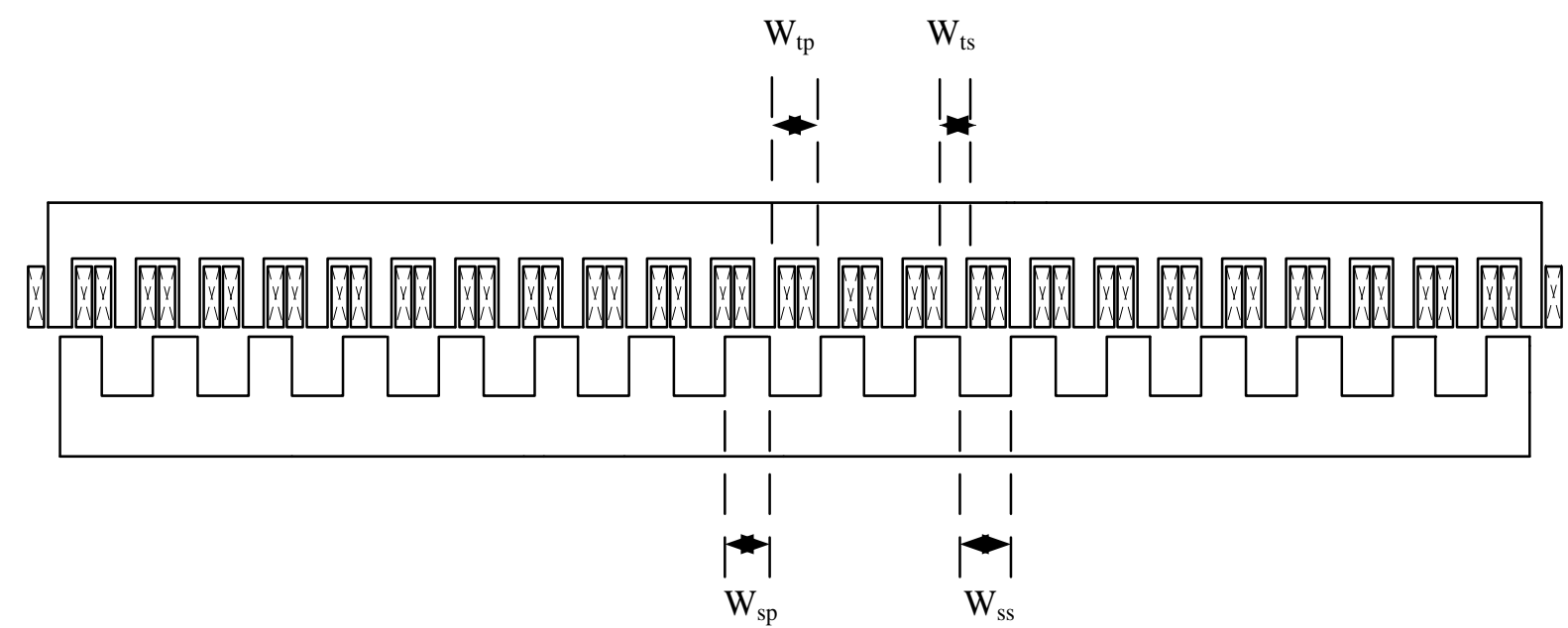

(c)

Figure 4. Model of LSRM with different slot -pole number; (a) 6s/4p; (b) 18s/12p; (c) 24s/16p 
Table 2. LSRM parameter after solidworks modelling

\begin{tabular}{lcccc}
\multicolumn{1}{c}{ Specification } & & \multicolumn{3}{c}{ Value } \\
& & $\mathbf{6 s} / \mathbf{4} \mathbf{p}$ & $\mathbf{1 8 s} / \mathbf{1 2 p}$ & $\mathbf{2 4 s / 1 6 p}$ \\
\hline Direct & & & \\
Max linear velocity, $V_{\text {max }}$ & {$[\mathrm{m} / s]$} & & 0.07 & \\
Acceleration time, $t_{a}$ & {$[\mathrm{~mm}]$} & & 10 & \\
Payload of the vehicle & {$[\mathrm{Kg}]$} & 0.5 & \\
Air gap length, & {$[\mathrm{g}]$} & & 1 & \\
Total length of translator, $L_{t r}$ & {$[\mathrm{~mm}]$} & & 165.5 & \\
Calculation & & & 40 & \\
Stack length, $L$ & {$[\mathrm{~mm}]$} & & 5 & \\
Stator yoke thickness, $C_{s y}$ & {$[\mathrm{~mm}]$} & & 10 & \\
Height of stator pole, $H_{s}$ & {$[\mathrm{~mm}]$} & & 12 & \\
Height of translator, $H_{r}$ & {$[\mathrm{~mm}]$} & & 5 & \\
Translator yoke thickness, $C_{r y}[\mathrm{~mm}]$ & & & \\
Other parameter & & & 4 & 2.1 \\
Stator Pole Width, $W_{s p}$ & {$[\mathrm{~mm}]$} & 15 & 4 & \\
Stator Slot Width, $W_{s s}$ & {$[\mathrm{~mm}]$} & 30.2 & 10.25 & 8.55 \\
Translator Pole Width, $W_{t p}$ & {$[\mathrm{~mm}]$} & 15 & 4 & 2.1 \\
Translator Slot Width, $W_{t s}$ & {$[\mathrm{~mm}]$} & 15.1 & 5.5 & 5 \\
\hline
\end{tabular}

\section{FEM ANALYSIS}

In this research, FEM software was used to get an overview of the appropriate structure based on design parameters. All components and their materials such as stator, translator and coil were assigned. The stator and translator are made of steel. Meanwhile, coil is made of copper. The next operation was the excitation coil, in which the number of coil turns for each coil of the three models will be set. Next was the mesh processing technique. Mesh was used to identify structure that was poorly designed. The mesh techniques consisted of length base, maximum length and maximum surface deviation for coil, stator, translator, and band. After the mesh setup was finished, the solution setups for stop time, time step, save field stop and step size were set. Lastly, the model underwent geometry and mesh check, whereby if there as an error or geometry not satisfied, the parameter will be checked or changed to a new value.

\subsection{Analysis parameter of average force and magnetic flux density}

Force is generated based on the principle of reluctance by the impulse of excited stator poles to align with the mover. For example, when the phase is excited, force is created between the stator and mover in positions where there is an impulse for the phase inductance to shift. Since the force is self-sufficient of the current flow direction, it enables the unidirectional currents to be used for excitation purposes. In this research, the average force can be simulated by using FEM simulation. The minimum target of average force is $10 \mathrm{~N}$. This requirement refers to the minimum load that LSRM can carry.

Flux density is the amount of magnetic flux in an area taken perpendicular to the magnetic flux direction. The magnetic flux density for this research can also be determined. Flux density can be simulated by using FEM and the target magnetic flux density must be lest than 1.8T because the maximum saturation curve of the material used in this research. The setting parameter by using FEM software is shown in Figure 5.

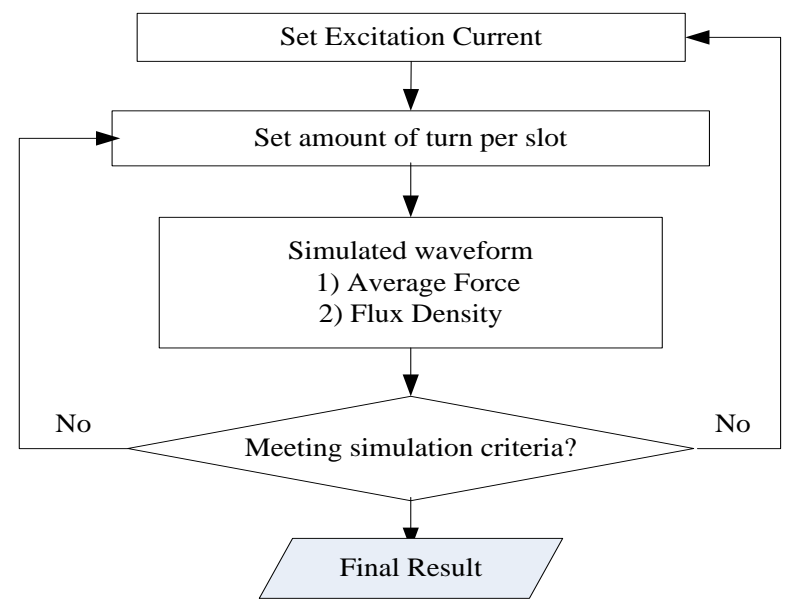

Figure 5. Analysis parameter of LSRM in FEM software 


\section{ANALYSIS PERFORMANCE OF LSRM}

This section explains the result of average force and magnetic flux density for the three different LSRM models, which were $6 s / 4 p, 18 s / 12 p$ and $24 s / 16 p$. The force can be indicated by Phase A, Phase B and Phase $\mathrm{C}$, which can be viewed after mesh is generated for the models. The performance of force can be indicated by the three phase formations, which were Phase A, Phase B and Phase C. All phases carried the same input current, whereby the current was injected into the winding which was operating at a phase difference of $120^{\circ}$. Figure 6 (a) shows an example of characteristic force when current of $1 \mathrm{~A}$ is used by the FEM simulation. In this simulation, each phase appearred as a sine wave since it was being input by DC. The average force which will be produced by this LSRM is a superposition of this force, as shown in that figure.

Meanwhile, the flux density of the motor must fulfil the requirement, which was lest than of $1.8 \mathrm{~T}$ since the stator was made up of steel. Figure 6(b) shows the shaded colour of magnetic flux density. Magnetic flux density was simulated by executing the isovalues with plots of shaded colours. After the completion of setting parameter by using FEM software, the magnetic flux density can be observed at all parts of the models.

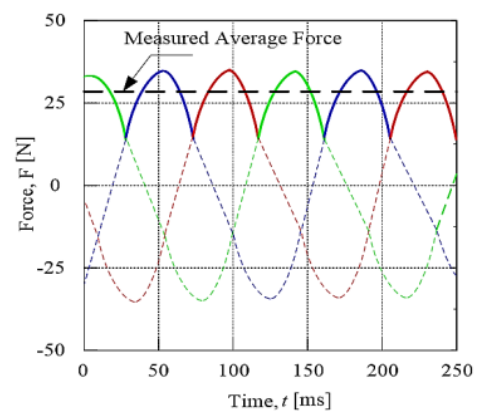

(a)

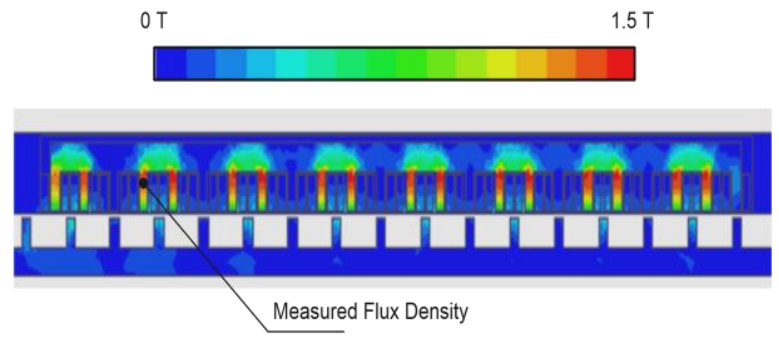

(b)

Figure 6. FEM simulation for 24s/16p at 1A; (a) average force and (b) magnetic flux density

Figure 7(a) shows the average force analysis for $6 \mathrm{~s} / 4 \mathrm{p}$. For $6 \mathrm{~s} / 4 \mathrm{p}$, the analysis was set at different number of turns, which were 130 turns, 370 turns and 3300 turns. The figure shows that the average force was gradually increased as the current and number of turns was increased. At minimum input current of $1 \mathrm{~A}$, the result for 3300 turns had the highest average force $(102.9 \mathrm{~N})$, while the average force for 130 turns was the lowest $(0.31 \mathrm{~N})$. Meanwhile, average force for 370 turns was $2.62 \mathrm{~N}$. On the other hand, for input current of $5 \mathrm{~A}$, the average force for 3300 turns was $349.53 \mathrm{~N}$, while the 370 turns and 130 turns produced an average force of $61.27 \mathrm{~N}$ and $8.03 \mathrm{~N}$, respectively. The result showed that the 3300 turns had the highest average force and 130 turns had the lowest. In addition, the model could provide enough average force to meet the targeted specification.

Figure 7(b) shows the magnetic flux density for 6s/4p LSRM model. Based on the graph, magnetic flux density was increased linearly as the input current increased to a higher value. It showed that for input current of $1 \mathrm{~A}$, the magnetic flux density for 130 turns, 370 turns and 3300 turns were $0.09 \mathrm{~T}, 0.47 \mathrm{~T}$ and $1.82 \mathrm{~T}$, respectively. It showed that the 3300 turns had the highest value, while the 130 turns had the lowest. For input current of $5 \mathrm{~A}$, the magnetic flux density for 130 turns, 370 turns and 3300 turns was $0.58 \mathrm{~T}, 1.44 \mathrm{~T}$ and $2.6 \mathrm{~T}$, respectively. The result showed that the 3300 turns maintained the highest magnetic flux density and the 130 turns was still with the lowest. Essentially, the requirement flux density must lest than $1.8 \mathrm{~T}$ because of the B-H saturation curve.

Figure 7(c) shows the average force for 18s/12p LSRM model, whereby the number of turns set for $18 \mathrm{~s} / 12 \mathrm{p}$ were 30 turns, 80 turns and 780 turns. From the graph, the input current ranged from $1 \mathrm{~A}$ to $5 \mathrm{~A}$. The average force produced by all turns showed a similar pattern at the lowest and highest input current. At input current of 1A, the average force for 30 turns, 80 turns and 780 turns was $0.062 \mathrm{~N}, 0.44 \mathrm{~N}$ and $43.68 \mathrm{~N}$, respectively. At input current of 5A, the average force for 780 turns was $301.04 \mathrm{~N}$. Meanwhile, average force for 30 turns and 80 turns was $1.56 \mathrm{~N}$ and $11.17 \mathrm{~N}$, respectively. In conclusion, the average force increased when the size of coil was smaller. Basically, size of coil affected the performance of average force.

Figure 7(d) illustrates the flux density for 18s/12p LSRM model. The value of flux density was affected by two variables, which were number of turns and input current. At input current of $1 \mathrm{~A}$, the magnetic flux density for 30 turns, 80 turns and 780 turns was $0.05 \mathrm{~T}, 0.16 \mathrm{~T}$ and $1.31 \mathrm{~T}$, respectively. The value continued to increase as the input current increased. On the other hand, at input current of $5 \mathrm{~A}$, the 30 turns obtained a magnetic flux density of $0.24 \mathrm{~T}$, while 80 turns and 780 turns obtained $0.79 \mathrm{~T}$ and $2.47 \mathrm{~T}$, respectively. It was concluded that magnetic flux density increased when number of turns and input current increased. 
Figure 7(e) shows average force for 24s/16p LSRM model. For this analysis, number of turns set for coil diameter of $0.1 \mathrm{~mm}, 0.3 \mathrm{~mm}$ and $0.5 \mathrm{~mm}$ was 20,70 and 600 turns per slot, respectively. When the input current was 1A, average force for 20 turns and 70 turns was $0.044 \mathrm{~N}$ and $0.39 \mathrm{~N}$, respectively. Meanwhile, for 600 turns, the average force was $28.36 \mathrm{~N}$. At current of 5A, the average force produced by 20 turns and 70 turns was $0.79 \mathrm{~N}$ and $9.83 \mathrm{~N}$, respectively. Average force for 600 turns was higher $(162.78 \mathrm{~N})$. In conclusion, performance of average force can be affected by the number of turns, input current and coil size. When input current increases, the performance of average force increases.

Figure 7(f) shows magnetic flux density for 24s/16p of LSRM model. The flux density gradually increased when the coil size decreased. With input current of 1A and 20 turns, the flux density was $0.04 \mathrm{~T}$, while with 70 turns, the flux density gradually increased to $0.15 \mathrm{~T}$. Meanwhile, the flux density increased to $1.23 \mathrm{~T}$ when number of turns was 600 . For input current of $5 \mathrm{~A}$, the flux density for 20 turns and 70 turns was increased to $0.23 \mathrm{~T}$ and $0.77 \mathrm{~T}$, respectively. As for the 600 turns, the flux density gradually increased to 2.37 T. From the graph, the $24 \mathrm{~s} / 16 \mathrm{p}$ LSRM model had potential to be selected because it was close to the targeted lest than $1.8 \mathrm{~T}$ characteristic of magnetic flux density.

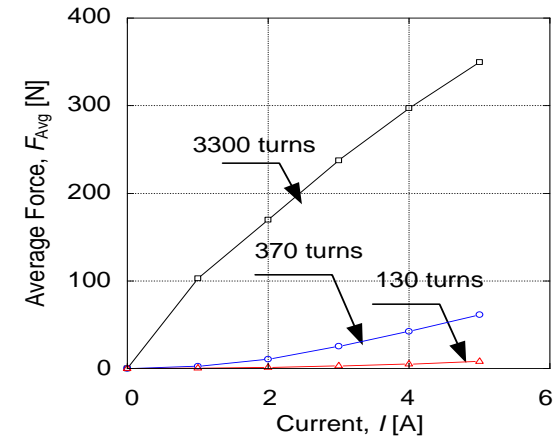

(a)

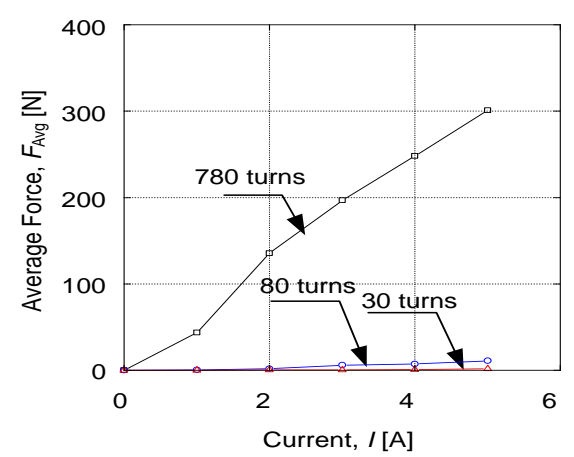

(c)

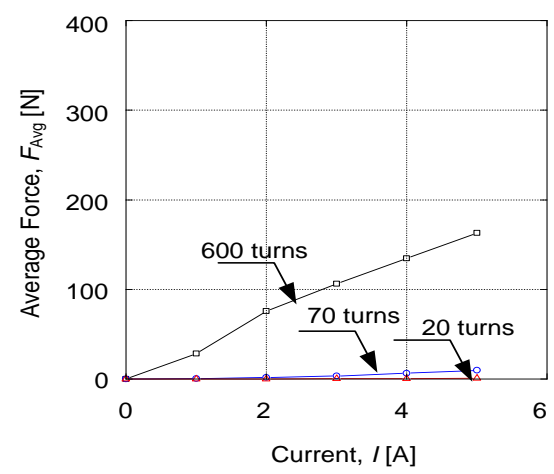

(e)

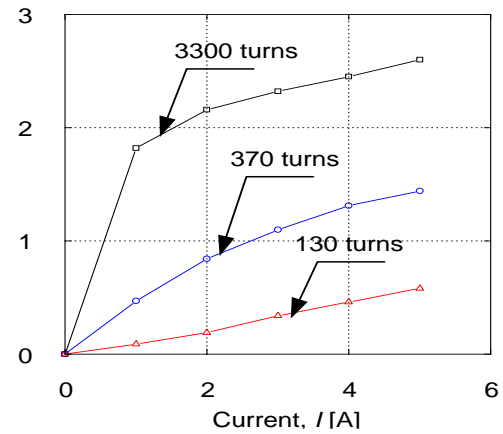

(b)

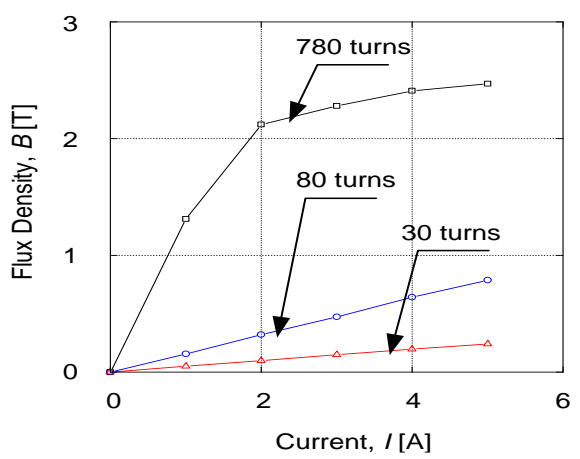

(d)

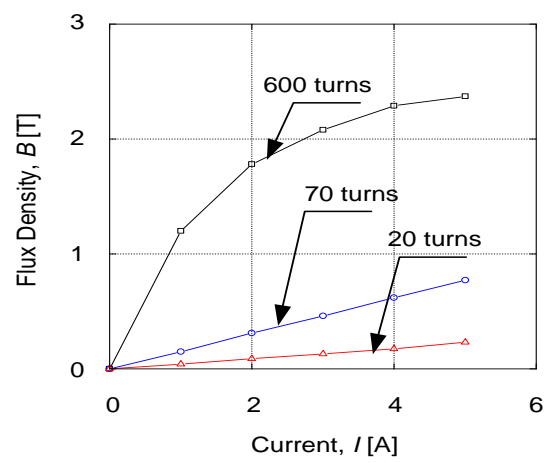

(f)

Figure 7. Analysis performance of LSRM; (a) average force for $6 \mathrm{~s} / 4 \mathrm{p}$; (b) magnetic flux density for $6 \mathrm{~s} / 4 \mathrm{p}$,

(c) average force for $18 \mathrm{~s} / 12 \mathrm{p}$, (d) magnetic flux density for $18 \mathrm{~s} / 12 \mathrm{p}$, (e) average force for $24 \mathrm{~s} / 16 \mathrm{p}$,

(f) magnetic flux density for $24 \mathrm{~s} / 16 \mathrm{p}$ 


\subsection{Performance selection}

The selection of the model depends on the analysis of average force and number of turns. The target performance for average force must reach $10 \mathrm{~N}$ and magnetic flux density must be lest than $1.8 \mathrm{~T}$. The suitable coil size was $0.1 \mathrm{~mm}$ when the input current was at $1 \mathrm{~A}$ due to the limitation of maximum current for specific coil size that can be accommodated. Table 3 shows the selected LSRM model. From the result, it was clear that the $24 \mathrm{~s} / 16 \mathrm{p}$ LSRM model was the best model as compared to the others. The model fulfilled the requirement/target, in which the average force must reach $10 \mathrm{~N}$ due to the $500 \mathrm{~g}$ payload. The magnetic flux density must be lest than $1.8 \mathrm{~T}$ because of the material B-H saturation curve.

Table 3. Selection the best model of LSRM at current $1 \mathrm{~A}$ with coil $0.1 \mathrm{~mm}$

\begin{tabular}{cccc}
\hline Performance & $6 \mathrm{~s} / 4 \mathrm{p}$ & $18 \mathrm{~s} / 12 \mathrm{p}$ & $24 \mathrm{~s} / 16 \mathrm{p}$ \\
\hline Average Force, $F_{\text {avg }}[\mathrm{N}]$ & 102.87 & 43.68 & 28.36 \\
Magnetic flux density, $B[\mathrm{~T}]$ & 1.82 & 1.31 & 1.23 \\
\hline
\end{tabular}

\section{CONCLUSION}

To conclude, the performance characteristics for $6 \mathrm{~s} / 4 \mathrm{p}, 18 \mathrm{~s} / 12 \mathrm{p}$, and $24 \mathrm{~s} / 16 \mathrm{p}$ LSRM models were presented for $\mathrm{F} \& \mathrm{~B}$ application. The three models with parameters, such as stack length, height, the thickness of translator and stator, were successfully simulated for average force $\left(F_{\text {avg }}\right)$ and magnetic flux density $(B)$. The result showed that the $24 \mathrm{~s} / 16 \mathrm{p}$ LSRM model had produced an average force $\left(F_{\text {avg }}\right)$ that suitable for carried 500g vehicle payload and achieved the requirement of magnetic flux density $(B)$, which was lest than $1.8 \mathrm{~T}$. From the analysis, its shown that average force $\left(F_{\text {avg }}\right)$ and Magnetic Flux Density $(B)$ continued to increase as the input current and number of turns increased.

\section{ACKNOWLEDGEMENTS}

The author would like to thank Ministry of Higher Education Malaysia, Universiti Teknikal Malaysia Melaka (UTeM) for providing the research grants FRGS/2018/FKE-CERIA/F00356.

\section{REFERENCES}

[1] M. Dursun, F. Koc, H. Ozbay, and S. Ozden, "Design of Linear Switched Reluctance Motor Driver forAutomatic Door Application," Int. J. Inf. Electron. Eng., vol. 3, no. 3, pp. 237-241, 2013, doi: 10.7763/ijiee.2013.v3.307.

[2] J. Caban, A. Nieoczym, W. Misztal, and D. Barta, "Study of operating parameters of a plate conveyor used in the food industry," IOP Conf. Ser. Mater. Sci. Eng., vol. 710, no. 1, 2019, p. 012020, doi: 10.1088/1757$899 x / 710 / 1 / 012020$

[3] D. Wang, D. Zhang, X. Du, and X. Wang, "Unitized Design Methodology of Linear Switched Reluctance Motor with Segmental Secondary for Long Rail Propulsion Application,” IEEE Trans. Ind. Electron., vol. 65, no. 12, pp. 9884-9894, 2018, doi: 10.1109/TIE.2018.2829690.

[4] J. G. Amoros, P. Andrada, and B. Blanque, "An analytical approach to the thermal design of a double-sided linear switched reluctance motor," 19th Int. Conf. Electr. Mach. ICEM, 2010, pp. 4-7, doi: 10.1109/ICELMACH.2010.5608298.

[5] J. F. Gieras, U. Technologies, and E. Hartford, "Electric Motors for Light Traction Electric Motors for Light Traction,” EPE journal, no. June, 2014, doi: 10.1080/09398368.2004.11463549.

[6] B. Ganji and M. H. Askari, "Analysis and modeling of different topologies for linear switched reluctance motor using finite element method," Alexandria Eng. J., vol. 55, no. 3, pp. 2531-2538, 2016, doi: 10.1016/j.aej.2016.07.017.

[7] E. W. T. Ngai, F. F. C. Suk, and S. Y. Y. Lo, "Development of an RFID-based sushi management system: The case of a conveyor-belt sushi restaurant," Int. J. Prod. Econ., vol. 112, no. 2, pp. 630-645, 2008, doi: 10.1016/j.ijpe.2007.05.011.

[8] B. P. Ruddy, "High force density linear permanent magnet motors: "electromagnetic muscle actuators," Doctoral dissertation, Massachusetts Institute of Technology, 2012, Available: http://dspace.mit.edu/handle/1721.1/78177

[9] D. Saha, P. Das, and S. Chowdhuri, "Design trends of linear induction motor (LIM) and design issues of a single sided LIM," Int. Conf. Control. Instrumentation, Energy Commun. CIEC 2014, no. November, pp. 431-435, 2014, doi: 10.1109/CIEC.2014.6959125.

[10] M. Seal and M. Sengupta, "Design, analysis and fabrication of a linear permanent magnet synchronous machine," Sadhana-Acad. Proc. Eng. Sci., vol. 42, no. 8, pp. 1419-1429, 2017, doi: 10.1007/s12046-017-0687-8.

[11] M. Gueye, "Linear Synchronous Motor," December, 2015, doi: 10.13140/RG.2.1.1626.3766.

[12] N. A. M. Nasir, F. A. bin Abdul Shukor, R. N. Firdaus, H. Wakiwaka, K. Tashiro, and M. Nirei, "Design of the permanent magnet linear synchronous motor for high thrust and low cogging force performance," Prog. Electromagn. Res. M, vol. 63, pp. 83-92, 2018, doi: 10.2528/PIERM17101907. 
[13] H. K. Bae, "A linear switched reluctance motor: converter and control," IEEE Trans. Ind. Appl., vol. 36, no. 5, pp. 1351-1359, 2000, doi: 10.1109/28.871284.

[14] J. G. Amoros and P. Andrada, "Sensitivity analysis of geometrical parameters on a double-sided linear switched reluctance motor," IEEE Trans. Ind. Electron., vol. 57, no. 1, pp. 311-319, 2010, doi: 10.1109/TIE.2009.2032208.

[15] B. Ganji and M. H. Askari, "Analysis and modeling of different topologies for linear switched reluctance motor using finite element method,” Alexandria Eng. J., vol. 55, no. 3, pp. 2531-2538, 2016, doi: 10.1016/j.aej.2016.07.017.

[16] J. Rigelsford, "Linear Synchronous Motors: Transportation and Automation Systems," Assem. Autom., vol. 20, no. 3, p. 3, 2000, doi: 10.1108/aa.2000.03320cad.017.

[17] M. Dursun, "Design of Linear Switched Reluctance Motor Driver forAutomatic Door Application," Int. J. Inf. Electron. Eng., vol. 3, no. 3, 2013, doi: 10.7763/ijiee.2013.v3.307.

[18] J. F. Llibre, N. Martinez, P. Leprince, and B. Nogarede, "Analysis and modeling of linear-switched reluctance for medical application," Actuators, vol. 2, no. 2, pp. 27-44, 2013, doi: 10.3390/act2020027.

[19] J. G. Amoros, P. Andrada, and B. Blanque, "An analytical approach to the thermal design of a double-sided linear switched reluctance motor," 19th Int. Conf. Electr. Mach. ICEM 2010, 2010, pp. 4-7, doi: 10.1109/ICELMACH.2010.5608298.

[20] L. Kolomeitsev et al., "Control of a linear switched reluctance motor as a propulsion system for autonomous railway vehicles," 2008 13th Int. Power Electron. Motion Control Conf. EPE-PEMC 2008, no. 02, 2008, pp. 1598-1603, doi: 10.1109/EPEPEMC.2008.4635495.

[21] N. Üstkoyuncu and K. Ramu, "Performance comparison of conventional and transverse ux linear switched reluctance motors,” Turkish J. Electr. Eng. Comput. Sci., vol. 23, no. 4, pp. 974-986, 2015, doi: 10.3906/elk-1305-214.

[22] W. C. Gan, K. K. C. Chan, G. P. Widdowson, and N. C. Cheung, "Application of linear switched reluctance motors to precision position control,” 2004 1st Int. Conf. Power Electron. Syst. Appl. Proc., vol. 2, no. 1, pp. 254-259, 2004.

[23] J. Chowdhury, G. Kumar, K. Kalita, K. Tammi, and S. K. Kakoty, "A review on linear switched reluctance motor," Raken. Mek., vol. 50, no. 3, pp. 261-270, 2017, doi: 10.23998/rm.65121.

[24] J. F. Llibre, N. Martinez, P. Leprince, and B. Nogarede, "Analysis and modeling of linear-switched reluctance for medical application," Actuators, vol. 2, no. 2, pp. 27-44, 2013, doi: 10.3390/act2020027.

[25] D. Wang, D. Zhang, X. Du, and X. Wang, "Unitized Design Methodology of Linear Switched Reluctance Motor with Segmental Secondary for Long Rail Propulsion Application," IEEE Trans. Ind. Electron., vol. 65, no. 12, pp. 9884-9894, 2018, doi: 10.1109/TIE.2018.2829690.

[26] H. K. Bae, B.-S. Lee, P. Vijayraghavan, and R. Krishnan "A linear switched reluctance motor: converter and control," IEEE Trans. Ind. Appl., vol. 36, no. 5, pp. 1351-1359, 2000, doi: 10.1109/28.871284.

[27] S. W. Zhao, W. X. Wang, X. Y. Yang, and N. C. Cheung, "Analysis and design of a Linear Switched Reluctance Motor with force improvement," 2013 5th Int. Conf. Power Electron. Syst. Appl. PESA 2013, no. 1, 2013, pp. 1-4, doi: 10.1109/PESA.2013.6828254.

[28] J. Garcia-Amoros, P. Andrada, and B. Blanque, "Linear Switched Reluctance Motors," Model. Control Switch. Reluctance Mach., 2020, doi: 10.5772/intechopen.89166.

[29] W. Zaafrane, M. Dursun, J. Khediri, and H. Rehaoulia, "A Novel Double Sided Linear Switched Reluctance Motor: Modeling and Performance Analysis,” Int. J. Electron. Electr. Eng., pp. 189-194, 2016, doi: 10.18178/ijeee.4.3.189-194.

\section{BIOGRAPHIES OF AUTHORS}

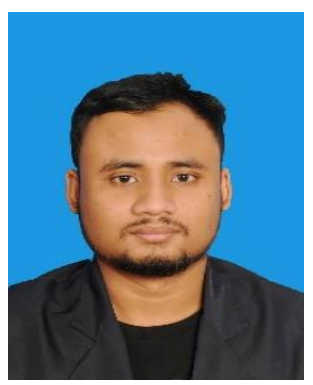

M. Asyraff Md Aris was born on 07 November 1994 at Klang, Selangor. He had received his B.Eng. in Electrical Engineering in 2020 from Universiti Teknikal Malaysia Melaka (UTeM). His research interest includes the field in machine design, electrical machine, and electric vehicle.

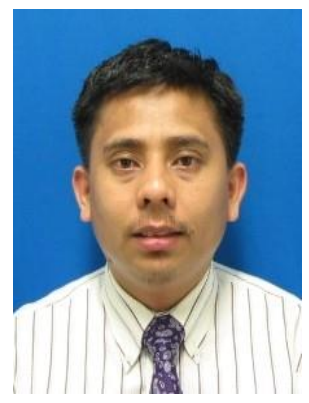

R. N. Firdaus was born on 02 May 1982 at Parit Buntar, Perak, Malaysia. He received B.Eng, M.Sc and Ph.D in Electrical Power Engineering from Universiti Putra Malaysia in 2016, 2009 and 2013, respectively. He is currently associate professor at Department of Power Electronics and Drives, Faculty of Electrical Engineering, Universiti Teknikal Malaysia Melaka. His research interest includes applied magnetics, electrical machines, magnetic sensor, and drives. 


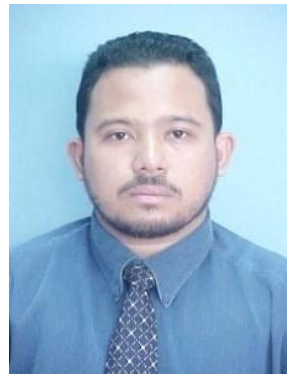

F. Azhar was born 24 October 1980. He received B.Eng in Electrical and Electronic Engineering from Universiti Putra Malaysia in 2002. Meanwhile, D. Eng. in Electrical Machine Design from Shinshu University, Nagano, Japan in 2015. He currently doctor at Department of Power Electronis and Drives, Faculty of Electrical Engineering, University Teknikal Malaysia Melaka. His research interest includes electrical machines, magnetic sensor, machine design, and electric vehicle.

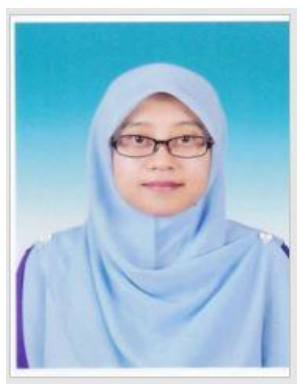

N. A. Mohd Nasir was born on 13 April 1993 at Gua Musang, Kelantan, Malaysia. She received her B.Eng. and M.Sc in Electrical Engineering from Universiti Teknikal Malaysia Melaka (UTeM) in 2016 and 2019, respectively. Currently, she is pursuing her study in PhD in Electrical Engineering from the same university. Her research study is in machine design and electric vehicle.

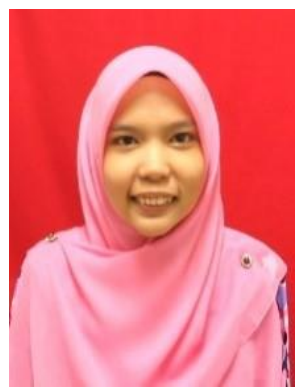

M. Z. Aishah was born on 09 November 1992 at Kuantan, Pahang, Malaysia. In 2015, she received her B.Eng. in Electrical Engineering from Universiti Teknikal Malaysia Melaka (UTeM). Currently, she is pursuing her study in PhD in Electrical Engineering from the same university. Her research study is in machine design and electric vehicle. 